\title{
Hubungan Agama Dan Negara Studi Terhadap Pemikiran Hidayat Nataatmadja Mengenai Hubungan Islam Dan Pancasila
}

\author{
Erik Darmawan \\ Dosen Universitas PGRI Palembang \\ edarmawan088@gmail.com
}

\begin{abstract}
Abstrak
Hubungan Islam dan Pancasila di Indonesia masih menjadi persoalan yang belum selesai. Sikap umat Islam Indonesia terbagi kedalam tiga golongan. Golongan fundamentalis menolak Pancasila sebagai dasar negara dan menginginkan Islam dijadikan dasar negara secara formal. Golongan nasionalis menolak Islam dihubungkan dengan persoalan kenegaraan. Golongan modernis menganggap tidak ada pertentangan antara Islam dengan Pancasila sehingga Pancasila dapat diterima sebagai dasar negara bagi bangsa Indonesia yang mayoritas muslim. Ketiga golongan tersebut meski memiliki perbedaan pandangan, namun mereka berangkat dari anggapan yang sama yaitu bahwa ada dua hal yang berbeda dan berdiri sendiri yaitu Islam dan Pancasila. Permasalahan yang diangkat dalam penelitian ini adalah bagaimanakah Islam dalam pemikiran Hidayat Nataatmadja ?, bagaimanakah Pancasila dalam pemikiran Hidayat Nataatmadja ? dan bagaimanakah hubungan Islam dan Pancasila dalam pemikiran Hidayat Nataatmadja ?. Melalui Pancasila yang secara substantif adalah nilai-nilai ajaran Islam, umat Islam Indonesia membangun ilmu-ilmu baru. Di atas ilmu-ilmu baru itu dibangun sistem-sistem kemasyarakatan baru. Dengan sistem-sistem kemasyarakatan baru itu umat Islam menata masyarakat baru. Dengan masyarakat baru yang telah tertata secara Islami itulah umat Islam membangun sebuah peradaban Islami tanpa nama Islam secara formal. Dengan bangunan peradaban Islami itulah umat Islam dapat bersaing dan mengungguli peradaban dunia lainnya. Secara cerdas dan bermartabat.
\end{abstract}

Kata Kunci : Islam, Pancasila, Hubungan Islam dan Pancasila.

\begin{abstract}
The relationship between Islam and pancasila in Indonesia is still an unfinished issue. The attitude of Indonesian Muslims is divided into three groups. The fundamentalists reject Pancasila as the basis of the state and want Islam to formally become the basis of the state. Nationalist groups reject Islam associated with state issues. The modernist group considers that there is no conflict between Islam and Pancasila so that the Pancasila can be accepted as the basis of the state for the Indonesian nation which is predominantly Muslim. The three groups, despite having different views, however, they depart from the same assumption, namely that there are two different and independent things, namely Islam and Pancasila. The problem raised in this study is how is Islam in the thought of Hidayat Nataatmadja? How is the Pancasila in the thought of Hidayat Nataatmadja? and how is the relationship between Islam and Pancasila in the thought
\end{abstract}

Tersedia Online di http://jurnal.radenfatah.ac.id/index.php/medinate 
of Hidayat Nataatmadja? Through Pancasila which is substantively the values of Islamic teachings, Indonesian Muslims build new sciences. Above the new sciences new social systems are built. With the new social systems, Muslims organize a new society. It is with this new society that has been organized in an Islamic manner that Muslims build a formal Islamic civilization without the name of Islam. With the building of Islamic civilization, Muslims can compete and outperform other world civilizations. Smart and dignified.

Keywords: Islam, Pancasila, Islamic Relations and Pancasila

\section{Pendahuluan}

Islam adalah agama yang sejak awal kehadirannya telah bersentuhan dengan permasalahan politik secara luas. Bahkan sejarah awal Islam dipenuhi dengan kisah kejayaan politik dan militer Nabi Muhammad saw (Mulia 2010, hlm.13). Apalagi jika dilihat keseluruhan sejarahnya, Islam adalah venture atau usaha yang tidak kenal berhenti untuk mewujudkan masyarakat yang dicita-citakan dan venture itu melibatkan orang-orang muslim dalam praktek semua bidang kegiatan hidup, dengan sendirinya termasuk dalam hal ini adalah politik (Azhar 1997, hlm. 4). Karena hal itulah umumnya para sejarafwan dan ahli politik menyimpulkan bahwa Nabi Muhammad bukan saja membawa agama baru tetapi juga membawa sebuah tatanan politik baru (Surwandono 2001, hlm. 5).

Dengan demikian praktik dan pemikiran politik Islam adalah aktifitas dan proses yang telah mengalami perjalanan sangat panjang dan belum pernah berhenti sampai hari ini. Selain disebabkan oleh hal-hal yang telah disebutkan pada alinea kesatu, hal ini juga dikarenakan pertama, Islam telah membuat sejarah selama lebih dari 14 abad, sehingga adalah suatu kenaifan jika kita menganggap dalam sejarah panjang itu segala sesuatunya bersifat tetap dan telah terhenti. Kedua, dalam perjalanan sejarahnya tersebut Islam memiliki perbendaharaan pengalaman maupun teori mengenai politik yang sangat kaya dan luas. Kedua hal ini menempatkan pembahasan mengenai politik Islam sebagai sesuatu yang terus berkembang (Mulia 2010, hlm. 3-14).

Bangsa Indonesia yang merdeka pada tahun 1945 mayoritas beragama Islam dengan wilayah yang meliputi bekas kesultanan-kesultanan Islam di kepulauan Nusantara namun pada saat kemerdekaan bersepakat mendirikan satu negara nasional dan pada akhirnya memilih Pancasila sebagai dasar negara (Maryam dkk. ed. 2009, hlm. 351). Pilihan tersebut telah menimbulkan dampak dalam perkembangan politik Islam di Indonesia dari sejak awal rencana kemerdekaan hingga saat ini. Baik dampak yang berupa mempertentangkan Islam dan Pancasila sebagai dasar Negara maupun juga dampak berupa akomodasi yaitu usaha-usaha untuk mengangkat titik temu antara Islam dan Pancasila.

Pertentangan dalam pembahasan mengenai hubungan Islam dan negara terjadi sejak tahun 1920. Saat itu terjadi polemik yang sangat tajam mengenai hubungan Islam dan negara, mengenai nasionalisme juga mengenai ideologi antara Mohammad Natsir yang mewakili kelompok politik Islam dengan Soekarno yang mewakili kelompok nasionalis (Suhelmi 2002, hlm. 2). Kemudian pertentangan itu berlanjut dalam sidang BPUPKI pada saat berlangsungnya pembahasan mengenai persoalan dasar negara, kemudian berlanjut mengerucut menjadi

Tersedia Online di http://jurnal.radenfatah.ac.id/index.php/medinate 
pertentangan antara dua pihak yaitu kelompok aktivis politik Islam dan kelompok nasionalis. Kelompok Islam berusaha memperjuangkan Islam sehingga memiliki kedudukan legal formal secara politik sebagai dasar negara. Berseberangan dengan itu, kelompok nasionalis menolak hubungan agama dan negara yang bersifat legalistik dan formalistik sebagaimana yang dituntut kelompok Islam (Hamid 2010, hlm. 375).

Namun di samping kedua pendapat tersebut terdapat pula pendapat ketiga yang bercorak akomodatif ditandai dengan sikap fleksibel yang bisa menerima segala kebijakan rezim terutama yang berkaitan dengan persoalan hubungan agama dan negara yang melahirkan pola simbiotik atau hubungan saling memberi dan menerima antara agama dan negara (al-Brebesy 1999, hlm. 50).

Dalam pandangan pola simbiotik, agama dan negara berada dalam posisi seimbang dengan hubungan timbal balik saling memerlukan. Agama memerlukan negara agar dapat berkembang dan mendapat legitimasi sedangkan negara memerlukan agama agar mendapatkan bimbingan etika dan moral spiritual (Hamid 2010, hlm. 378). Tokoh-tokoh yang berpandangan simbiotik meyakini bahwa meskipun agama Islam tidak menjadi agama negara secara formal namun Islam dapat memberikan sumbangan besar berupa etika dan moral untuk penataan kehidupan bernegara.

Hidayat Nataatmadja (selanjutnya Nataatmadja) adalah pemikir modern muslim Indonesia mengemukakan pandangan yang berbeda. Nataatmadja mengemukakan bahwa Islam, NKRI, Pancasila adalah satu. Kesatuan antara Islam, NKRI dan Pancasila memiliki pola yang khas. Kesatuan tersebut bersifat legal tetapi tidak bersifat formalis atau simbolik.

Dalam naskah yang berjudul Bedah Pembaharuan semesta di dunia ilmu, Nataatmadja mengemukakan pemikirannya mengenai Islam, NKRI, Pancasila dan UUD'45. Nataatmadja memandang bahwa Islam, NKRI, Pancasila dan UUD'45 sebagai satu kesatuan. Keempat hal itu merupakan bagian dari perjalanan sejarah Islam yang akan menjadi starting point bagi terbangunnya kembali peradaban Islam untuk kali yang kedua. Nataatmadja berpandangan bahwa Proklamasi kemerdekaan RI adalah bagian dari perjalanan sejarah Islam dan Pancasila serta UUD 45 adalah bagian dari ajaran Islam karena dirumuskan dari pengalaman dan perjalanan hidup umat Islam Indonesia.

Pemikiran Nataatmadja mengenai persoalan hubungan Islam dan negara dalam hal ini Islam dan Pancasila, berangkat dari keprihatinannya melihat kondisi umat Islam Indonesia yang berada dalam kegamangan sikap, antara ke-Indonesiaan sebagai bagian dari bangsa Indonesia di satu sisi dan ke-Islaman sebagai seorang muslim. Menurut Nataatmadja kegamangan sikap ini disebabkan oleh persoalan hubungan Islam dan Pancasila yang belum selesai. Islam dan Pancasila masih diposisikan sebagai dua hal yang berbeda dan berdiri sendiri-sendiri. Nataatmadja berpendapat hal ini sebagai kekeliruan dan harus diluruskan. Nataatmadja berpendapat Islam dan Pancasila adalah satu kesatuan.

Pemikiran Nataatmadja tersebut sangat menarik dikarenakan pemikirannya adalah hasil kegiatan intelektualitas mengenai hubungan Islam dan negara yang merupakan bagian dari perjalanan dan perkembangan pemikiran politik Islam di Indonesia. Nataatmadja tidak saja 
mengangkat persoalan mengenai hubungan Islam dan Pancasila namun juga memberikan solusi terhadap persoalan dalam hubungan keislaman dan keindonesiaan yang berlarut-larut.

\section{Rumusan Permasalahan}

Dari latar belakang tersebut maka penulis tertarik untuk meneliti pemikiran Nataatmadja dengan mengangkat tiga permasalahan yaitu :

1. Bagaimanakah pemikiran Hidayat Nataatmadja Mengenai Islam ?

2. Bagaimanakah pemikiran Hidayat Nataatmadja Mengenai Pancasila?

3. Bagaimanakah pemikiran Hidayat Nataatmadja Mengenai Hubungan Islam dan Pancasila?

\section{Kerangka Teori}

\section{Pemikiran Hidayat Nataatmadja mengenai Hubungan Islam dan Pancasila}

Nataatmadja mengemukakan bahwa ber-Islam mengandung konsekuensi yaitu adanya kewajiban yang melekat pada setiap muslim untuk berperan serta dalam membangun peradaban Islam. Dalam konteks kehidupan bernegara, kewajiban itu melekat pula pada setiap muslim yang menjadi warga negara di negara manapun. Baik dalam kondisi sebagai mayoritas maupun sebagai minoritas. Umat Islam berkewajiban menjadikan Islam sebagai landasan pembangunan dan penataan masyarakat secara legal di dalam negara itu tetapi tanpa harus menampilkan Islam secara formal.

Pemikiran Nataatmadja tersebut melahirkan dua bagian terpenting dari pemikiran Nataatmadja selanjutnya, -dan hal ini belum pernah diajukan oleh modernis Muslim Indonesia yang lain- pertama, Nataatmadja secara tegas mendudukkan Islam sebagai landasan untuk membangun peradaban Islam masa depan yang disebutnya sebagai peradaban Islami Pancasila. Kedua, Nataatmadja memberikan konsep mengenai bagaimana tahapan yang harus dilalui dalam membangun sebuah peradaban Islami di Indonesia yang berkelas dunia. Nataatmadja meyakinkan, dengan Peradaban Islami Pancasila yang berkelas dunia itulah kaum muslimin Indonesia dapat mengalahkan sistem-sistem dunia yang sedang berkuasa saat ini, dan mewujudkan sebuah peradaban dunia yang membahagiakan semua penduduk bumi atau rahmatan lil 'alamin.

\section{Metode Penelitian}

Penelitian ini adalah penelitian kepustakaan atau library research. Dalam penelitian ini dilakukan penggalian komprehensif terhadap pemikiran Nataatmadja secara analitis dan kritis. Pemikiran tersebut terkandung di dalam buku-buku dan naskah-naskah tulisan Hidayat Nataatmadja yang memuat pemikirannya mengenai Islam, Pancasila dan hubungan antara Islam dan Pancasila. Sehingga tergambar dengan jelas bagaimanakah hubungan Islam dan negara dalam pemikiran Hidayat Nataatmadja. Menurut Syahrin (2000, hlm. 18), dalam Studi Tokoh Dalam Pemikiran Islam, dalam studi kepustakaan yang menstudi pemikiran seorang tokoh, untuk mengambil data berupa pemikiran seorang tokoh dilakukan tiga tahapan kerja yaitu Inventarisasi, Evaluasi kritis dan Sintesis. Pada tahap Inventarisasi dilakukan penghimpunan sumber-sumber data baik sumber primer maupun sekunder. Sumber-sumber data tersebut diseleksi, dibaca,

Tersedia Online di http://jurnal.radenfatah.ac.id/index.php/medinate 
dicatat dan dikategorisasi. Pada tahap Evaluasi kritis dilakukan dilakukan analisis baik berupa pembandingan maupun analisis dengan melihat kekuatan serta kelemahan dari data yang dimiliki. Pada tahap Sintesis dilakukan pemilihan terhadap unsur-unsur yang memperkaya penelitian kemudian disusun secara sistematis untuk menjawab permasalahan penelitian ini.

Dalam menstudi sebuah data, jika studi dilakukan hanya untuk meninjau isi data maka teknik analisis isi atau content analysis sudah cukup memadai. Namun jika studi tersebut tidak hanya sekedar kegiatan menggali data-data saja, tetapi juga melibatkan kegiatan interpretasi peneliti terhadap data-data tersebut, maka teknik analisis data yang dibutuhkan adalah teknik hermeneutik.

\section{Hasil dan Diskusi}

\section{Meletakkan Islam Sebagai Landasan Bagi Ideologi Pancasila}

Nataatmadja mengemukakan, cara kita berpikir menentukan bagaimana cara kita menilai dan menentukan bagaimana cara manusia berperilaku. Ketiga hal itu, cara berpikir, menilai dan berperilaku sangat menentukan corak kehidupan yang di bangun (Nataatmadja 1982, hlm. 264).

Satu hal penting yang harus disadari adalah bahwa bagaimana cara kita berpikir sangat ditentukan oleh sumber rujukan pikiran kita. Kesalahan dalam mengambil sumber rujukan akan menghasilkan cara berpikir yang salah. Cara berpikir yang salah akan menghasilkan cara menilai yang salah pula dan cara menilai yang salah akan menghasilkan cara berperilaku yang salah. Keempat kesalahan itu (sumber rujukan pikiran, cara berpikir, cara menilai, cara berperilaku), hanya akan menghasilkan corak kehidupan yang salah pula (Nataatmadja 1982, hlm. 264).

Untuk itu agar umat Islam dan bangsa Indonesia dapat mewujudkan tugasnya membangun peradaban Islami Pancasilais maka yang pertamakali harus dilakukan adalah meletakkan Islam sebagai landasan Ideologi Pancasila yang dapat penulis gambarkan dalam bagan berikut :

\section{Bagan 1.}

\section{Substansi Ajaran Islam Sebagai Sumber Rujukan}

Nilai-nilai Dasar Dalam Pancasila

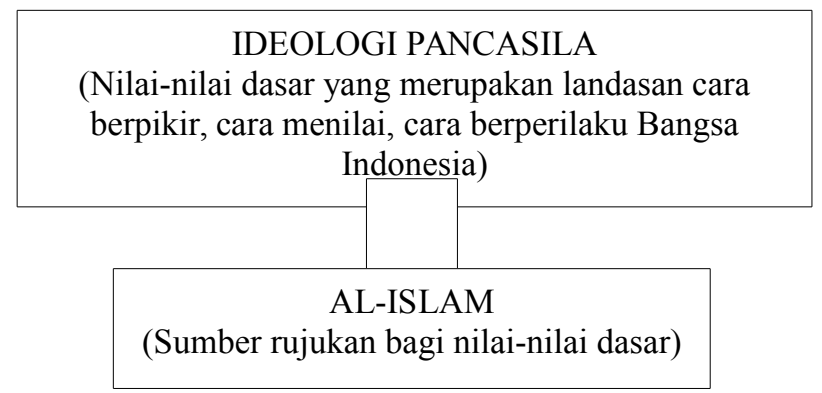

Dalam bagan tersebut tergambar posisi Islam sebagai fondasi bagi bangunan ideologi Pancasila yang berada di atasnya. Dalam posisi tersebut Islam berfungsi sebagai satu-satunya sumber rujukan bagi Pancasila. Nataatmadja menegaskan hanya Islam yang mampu menempati posisi ini. Karena hanya Islam yang memiliki konsep-konsep dasar kehidupan manusia yang utuh dan universal sesuai fitrah kemanusiaan.

Tersedia Online di http://jurnal.radenfatah.ac.id/index.php/medinate 
Langkah pertama yang diajukan Nataatmadja ini menurut pendapat peneliti, ibarat membuka jalan raya yang lebar bagi Islam untuk dapat dioperasionalisasikan dalam seluruh aspek kehidupan berbangsa dan bernegara,

Inilah langkah inisiasi yang kini terbuka bagi kaum Muslimin, sehingga melalui dakwah Islami kita mampu menegakkan ajaran Islam dalam dunia empiris. Kita juga bisa berdakwah dalam dunia politik, berbicara mengenai kesaktian Pancasila, karena Pancasila bisa sepenuhnya diterangkan dengan ajaran agama. Tiada lagi kerancuan makna antara ideologi dan agama. Ideologi tetap dipandang bersumber pada ide, dalam hal ini ide yang tercetus menjelang Hari Proklamasi yang bersejarah. Tiada secuil pun alasan bagi kaum muslimin untuk menghianati landasan kebangsan yang telah dituangkan ke dalam bentuk Pancasila dan UUD 45, karena kini kaum Muslimin bisa memberikan makna Islami terhadap kesemua sila yang terdapat dalam filsafat negara (Nataatmadja 1984b, hlm. 189).

\section{Tahapan Pembangunan Peradaban Islami Pancasila}

Nataatmadja membagi tahapan pembangunan peradaban Islami Pancasila ke dalam 5 (lima) tahap yang akan di uraikan sebagai berikut :

\section{Meletakkan Pancasila Sebagai Landasan Membangun Ilmu-Ilmu Baru}

Dengan ideologi Pancasila yang telah dibangun di atas substansi nilai-nilai ajaran Islam, maka tugas suci yang diberikan kepada bangsa Indonesia selanjutnya adalah meletakkan ideologi Pancasila sebagai landasan pijak bagi pembangunan ilmu-ilmu baru. Mustahil kaum muslimin mampu membangun peradaban Islami, tanpa terlebih dahulu membangun ilmu-ilmu yang Islami sebagai alatnya. Mustahil pula kaum muslimin mampu membangun Ilmu-ilmu Islami tanpa mempersiapkan terlebih dahulu landasan atau fondasinya (Nataatmadja 1982, hlm. 18).

Landasan atau fondasinya adalah Ideologi Negara Pancasila itu sendiri. Ideologi negara tidak akan pernah dapat dioperasionalisasikan selama tidak diturunkan menjadi teori-teori atau ilmu-ilmu. Sehingga dengan demikian fungsi ilmu-ilmu tersebut adalah sebagai "perpanjangan tangan" ideologi. Melalui ilmu-ilmu itu ideologi mewujudkan cita-citanya. Suatu bangsa tidak akan pernah mampu mewujudkan cita-citanya tanpa menggunakan ilmu miliknya sendiri apalagi menggunakan sains-sains ${ }^{1}$ yang bersumber dari ideologi lain. Karena hanya bangsa itulah yang tahu siapa dirinya, apa cita-citanya dan bagaimana cara mencapainya (Nataatmadja 1985, hlm. 176).

1 Nataatmadja (1984a, hlm. 202), membedakan secara tegas antara "ilmu” dan "sains". "Ilmu" dan "sains" sepintas memang seolah sama namun keduanya sebenarnya sangat bertolak belakang. Istilah ilmu berasal dari kosakata al-Qur'an sedangkan sains berasal dari kosakata Barat. Makna, isi dan tujuan "ilmu” hanya dimiliki oleh Islam. Karena itu tentunya missi yang terkandung di dalam ilmu adalah missi Islam pula. Hal ini bertolak belakang dengan "sains" yang dikembangkan dan diisi oleh masyarakat berideologi sekuler-liberal-kapitalis tentunya missi yang terkandung di dalam sains adalah missi sekuler-liberal-kapitalis pula.

Tersedia Online di http://jurnal.radenfatah.ac.id/index.php/medinate 
Menurut Nataatmadja (2001, hlm. 42), hal ini dikarenakan al-Qur'an tidak dapat langsung dijadikan teori-teori atau ilmu-ilmu. Sebab al-Qur'an adalah cikal-bakal ilmu. Al-Qur'an memberikan nilai-nilai dasar nya saja yang bersifat kekal dan universal. Sedangkan untuk pengembangan ilmu hal itu diserahkan kepada akal manusia sesuai dengan kebutuhan zaman masing-masing (Nataatmadja 2007, hlm. 96).

2. Membangun Ilmu-Ilmu Pancasilais di atas Ideologi Pancasila

Nataatmadja mengemukakan setelah menempatkan Pancasila sebagai landasan ilmu maka langkah berikutnya adalah membangun ilmu-ilmu baru di atas landasan tersebut. Atau dalam istilah lain ideologi Pancasila diturunkan menjadi berbagai disiplin-disiplin ilmu yang Pancasilais. Ilmu adalah alat untuk merekayasa kehidupan. Sehingga kehidupan seperti apa yang akan dibentuk sangat tergantung kepada ilmu pembentuknya. Sedangkan corak ilmu ditentukan oleh ideologi yang menjadi landasannya. Corak ideologi sendiri ditentukan oleh sumber rujukannya. Karena itu Nataatmadja berpendapat bahwa agama, ideologi dan ilmu adalah satu kesatuan fundamental yang tidak bisa dipisahkan. Memisahkan ketiganya hanya menghasilkan bencana (Nataatmadja, 1982, hlm. 24).

Dengan demikian, Islami tidaknya suatu ilmu akan dapat dievaluasi dengan mengukur berpijak atau tidaknya ilmu itu pada landasan agama (Nataatmadja 1985, hlm. 127). Karena Allah adalah pemilik ilmu maka validator ilmu tentu saja adalah Allah, ditinjau dari sesuai tidak ilmu itu dgn tujuan yang Allah gariskan (Nataatmadja 1985, hlm. 40).

Dengan demikian Ilmu-ilmu baru tersebut bisa saja disebut dengan ilmu-ilmu Pancasilais, karena ia berpijak di atas landasan ideologi Pancasila. Atau bisa juga disebut sebagai ilmu-ilmu Islami karena ia bersumber pada ajaran Islam. Nataatmadja menegaskan hanya Islam yang mampu menempati posisi ini. Karena hanya Islam yang memiliki konsep-konsep dasar kehidupan manusia yang utuh dan universal sesuai fitrah kemanusiaan.

3. Membangun Sistem-Sistem Kemasyarakatan Pancasilais di atas Ilmu-Ilmu Pancasilais

Setelah membangun Ilmu-Ilmu Pancasilais, tahap selanjutnya adalah membangun sistemsistem kemasyarakatan Pancasilais di atas Ilmu-Ilmu Pancasilais tersebut.

Nataatmadja mengemukakan, sebuah masyarakat Pancasilais mustahil bisa dibangun menggunakan sistem-sistem kemasyarakatan yang bersumber dari ilmu-ilmu Barat. Karena itu membangun sistem-sistem kemasyarakatan Pancasilais sebagai kelanjutan dari pembangunan Ilmu-Ilmu Pancasilais adalah keharusan. Membangun sistem-sistem kemasyarakatan yang tidak bersumber pada ajaran agama hanya akan menghasilkan masyarakat yang berperilaku aneh dan menyimpang sebagaimana diungkapkan Nataatmadja :

Tidakkah aneh di negara paman Mao kebebasan sex dibekukan, dan bagaimana kebebasan sex melonggar di negara yang mayoritas warganya mengaku Islam ! Ya, siapa yang bisa mengerti bagaimana di suatu negara yang berlandaskan Pancasila pencurian, korupsi dan manipulasi berlarut-larut melebihi apa yang terjadi di negara-negara atheis (Nataatmadja 1982, hlm. 265).

Miriam Budiarjo mengemukakan logika yang sama sebagai berikut :

Terlepas dari polemik apakah Islam mengajarkan atau menuntut didirikannya negara atau tidak, pada kenyataannya umat Islam membutuhkan sebuah sistem ketatanegaraan yang Islami. Sistem ketatanegaraan ini dibutuhkan untuk menjamin lahirnya kebijakan publik -kebijakan

Tersedia Online di http://jurnal.radenfatah.ac.id/index.php/medinate 
publik Islami yang menegakkan keadilan dan perdamaian. Untuk menegakkan kebijakankebijakan publik tersebut dibutuhkan kekuasaan baik itu berupa organisasi politik ataupun negara. Persoalannya, jika yang ingin ditegakkan dalam kebijakan-kebijakan publik itu adalah prinsip-prinsip Islam, maka seluruh perangkat atau sistem-sistem yang melingkupinya harus Islami pula. Alangkah kurang tepatnya jika dalam menegakkan prinsip-prinsip Islam itu menggunakan sistem-sistem non Islami.

Peneliti berpendapat bahwa terdapat kesamaan pemikiran antara Nataatmadja dan Miriam Budiarjo yaitu bahwa umat Islam membutuhkan sistem-sistem kemasyarakatan dan kelembagaan politik yang legal untuk mewujudkan nilai-nilai ajaran Islam dalam kehidupan nyata.

Perbedaannya, Miriam tidak memberikan gambaran apa dan bagaimana yang harus dilakukan umat Islam Indonesia selanjutnya. Tampaknya Miriam terjebak pada pola pikir bahwa jika ingin membangun sistem-sistem Islami yang legal mau tidak mau Islam harus diformalkan sebagai institusi politik, sebagaimana yang peneliti baca pada buku-buku yang diterbitkan oleh organisasi Hizbut Tahrir.

Sedangkan Nataatmadja memberikan sebuah jalan, bagaimanakah nilai-nilai Islam dapat diwujudkan menjadi sistem-sistem kemasyarakatan di Indonesia secara legal tanpa menjadikan Islam sebagai institusi formal, tetapi dengan itu justeru umat Islam dapat dengan leluasa mengIslamkan seluruh bangsa Indonesia bahkan seluruh umat manusia. Yaitu dengan membangun sistem-sistem kemasyarakatan Pancasilais di atas ilmu-ilmu Pancasilais. Atau dengan kata lain Ilmu-ilmu Pancasilais tersebut selanjutnya diturunkan menjadi sistem-sistem kemasyarakatan untuk kemudian dipergunakan membangun dan menata masyarakat (Nataatmadja 1982, hlm. 56).

\section{Membangun Tatanan Masyarakat Pancasilais di atas Sistem-Sistem Kemasyarakatan Pancasilais}

Sebagaimana telah dibahas sebelumnya, Nataatmadja mengemukakan bahwa persoalan kehidupan manusia sebenarnya sama yaitu seputar persoalan kemerdekaan, keadilan dan kesejahteraan. Hal ini adalah persoalan-persoalan mendasar di dalam masyarakat yang senantiasa hendak dicapai oleh seluruh umat manusia atau disebut juga sebagai fitrah manusia.

Persoalan mendasar atau fitrah ini hanya bisa bisa dijawab oleh Pencipta Manusia. Manusia tidak akan pernah mampu menjawabnya. Manusia hanya mampu menurunkan nilai dasar untuk dioperasionalkan. Karena itu jika ingin membangun sebuah tatanan masyarakat yang terpenuhi persoalan mendasar atau fitrahnya itu maka yang harus dilakukan adalah dengan membangun sebuah tatanan masyarakat dengan menggunakan sistem-sistem kemasyarakatan yang dibangun di atas ilmu-ilmu agamawi (Nataatmadja 2013, hlm. 17).

Apabila kita ingin membangun sebuah masyarakat Pancasilais maka tentunya masyarakat itu harus dibangun dan ditata menggunakan sistem-sistem kemasyarakatan Pancasilais pula. Sistem-sistem kemasyarakatan Pancasilais itu tentunya harus dibangun di atas ilmu-ilmu yang Pancasilais pula. Tentunya untuk menghasilkan ilmu-ilmu yang Pancasilais maka ilmu-ilmu tersebut harus dibangun di atas Ideologi Pancasila yang sebelumnya telah di isi dengan nilai-nilai ajaran Islam.

Tersedia Online di http://jurnal.radenfatah.ac.id/index.php/medinate 
Cita-cita nasional untuk membangun manusia Pancasila yang seutuhnya dan juga masyarakat yang Pancasilais tentu saja tidak bisa dilakukan dengan menggunakan sistem-sistem Barat

5. Membangun Peradaban Islami Pancasila di atas Tatanan Masyarakat Pancasilais

Nataatmadja (2007, hlm. 59), mengemukakan, berjihad melalui jalur medan pembangunan dan penguasaan ilmu adalah satu-satunya pilihan karena ilmu adalah satu-satunya alat untuk membangun peradaban. Nataatmadja menegaskan pula bahwa Islam baru akan benarbenar terlihat sebagai sebuah sistem yang baik, benar dan unggul hanya jika ia telah berwujud satu peradaban yang utuh. Dalam bentuk seperti itulah umat Islam baru bisa menghadapi dan mengalahkan seluruh sistem-sistem kafir termasuk peradaban Barat dengan cara yang cerdas dan terhormat.

Hal ini perlu segera dilakukan sebagai langkah penyelamatan terhadap bumi dan seluruh isinya. Apabila kita perhatikan manusia modern saat ini dengan segala keunggulannya dibanding dengan manusia-manusia zaman jahiliyah Arab dahulu maka kita akan menemukan kenyataan yang teramat aneh. Ternyata segala keunggulan manusia modern berhenti pada sebuah titik runyam. Kita hidup dalam kerancuan, dunia sosial yang justeru tidak dapat kita mengerti. Segala keterampilan dan teknologi yang maju justeru menjadi sumber penyakit sosial baru yang lebih gawat dari penyakit-penyakit sosial dimasa lalu (Nataatmadja 1985, hlm.120).

Maka umat Islam wajib untuk segera bangkit dari tidur panjangnya dan membangun sebuah peradaban yang maslahat bagi seluruh makhluk bumi, di atas masyarakat yang telah dibangun dan ditata dengan ajaran Islam (Nataatmadja 1985, hlm.119). Hanya masyarakat dengan Islam yang hidup, Islam yang berbentuk nilai-nilai yang teraplikasi nyata di dalam kehidupan masyarakat sehari-hari, Islam yang telah menjadi jiwa kehidupan, menyata dalam setiap pikiran, sikap dan perilaku baik individu maupun masyarakat, yang mampu membangun sebuah peradaban (Nataatmadja 1984a, hlm. 231, 1985, hlm.119).

Dengan Islam yang sudah terbentuk menjadi satu peradaban yang utuh, maka umat Islam bukan hanya mampu mengungguli peradaban-peradaban lain tetapi juga pasti akan mampu mengIslamkan seluruh manusia seisi bumi. Karena dengan peradaban yang unggul dan mendunia maka nilai-nilai ajaran Islam akan mempengaruhi cara berpikir, cara bersikap dan berperilaku semua manusia. Hanya dengan cara seperti ini kaum muslimin membuktikan bahwa mereka memahami ajaran Islam (Nataatmadja 1982, hlm. 56).

"bahwa dengan Islam dalam bentuk yang utuh seperti inilah maka nilai-nilai ajaran Islam dapat ditegakkan di dunia nyata", "mengungguli peradaban-peradaban lain" (Nataatmadja 1982, hlm. 76), dan bahkan kaum muslimin akan dapat mengislamkan manusia seluruh dunia lewat pengaruh cara berpikir, bersikap dan berperilaku yang berpijak pada ajaran Islam (Nataatmadja 1982, hlm. 56, 1984b, hlm.147).

Mengenai pertentangan atau konflik dan tarik menarik yang terjadi antara Islam dan Pancasila Nataatmadja menjawab bahwa melalui konsep yang ia tawarkan kita dapat melihat bahwa pertengkaran antara Islam dengan Pancasila adalah disebabkan kedunguan kaum muslimin yang tidak melanjutkan menegakkan agama di dalam ideologi (Nataatmadja 1985, hlm 283).

Tersedia Online di http://jurnal.radenfatah.ac.id/index.php/medinate 
Maka dapat dibenarkan pendapat Nataatmadja (1985, hlm. 109), yang menegaskan bahwa satu-satunya jalan untuk membangun sebuah tatanan masyarakat atau peradaban Islam adalah membangun Ilmu-ilmu yang berlandaskan al-Qur'an dan membangun sistem kemasyarakatan berdasarkan ilmu-ilmu tersebut.

\section{KESIMPULAN}

Mengenai Pancasila Hidayat Nataatmadja mengemukakan bahwa Prinsip-prinsip dalam Pancasila bukanlah sesuatu yang asing bagi umat Islam Indonesia karena Pancasila lahir dari masyarakat Muslim Indonesia sebagai landasan nilai dalam perjuangan kemerdekaan. Prinsipprinsip dalam Pancasila diambil dari prinsip-prinsip pokok atau substansi nilai dari ajaran Islam. Hal ini dilakukan pertama kali oleh Sarekat Islam. Sehingga sesungguhnya Pancasila adalah bagian yang tidak terpisahkan dari umat dan agama Islam.

Islam berposisi sebagai sumber nilai bagi Pancasila dan Pancasila berposisi sebagai alat operasional bagi Islam di Indonesia. Keduanya disatukan menjadi sumber rujukan pikiran, sikap dan perilaku bangsa Indonesia maka di atas keduanya, umat Islam Indonesia harus bersegera membangun ilmu-ilmu baru yang Islami atau Pancasilais untuk keperluan membangun sistemsistem penataan masyarakat baru yang Islami atau Pancasilais pula. Ilmu-ilmu dan sistem-sistem Islami ini dibutuhkan untuk menggantikan sains-sains dan sistem-sistem Barat yang telah mencemari pikiran, sikap dan perilaku bangsa Indonesia yang berakibat tidak tercapainya citacita nasional bangsa Indonesia. Dengan ilmu-ilmu dan sistem-sistem baru yang Islami atau Pancasilais itulah pikiran, sikap dan perilaku masyarakat diisi dengan nilai-nilai Islam. Kemudian masyarakat dibangun dan ditata dengan pikiran, sikap dan perilaku yang Islami. Dengan demikian barulah akan lahir masyarakat dan peradaban yang Islami atau Pancasilais di Indonesia. Inilah kesatuan antara Islam dengan Pancasila yang seharusnya telah terjadi sejak awal Indonesia merdeka. Namun, proses tersebut terputus bahkan dari sejak awal Indonesia merdeka hingga sekarang.

Saat ini tugas besar untuk menyatukan kembali Islam dan Pancasila berada ditangan umat Islam Indonesia. Umat Islam harus berjuang mengembalikan Islam dan Pancasila pada tempatnya sebagai sumber rujukan bagi pikiran, sikap dan perilaku bangsa Indonesia seluruhnya. Agar Islam dan umat Islam mendapatkan kembali peran dan fungsinya sebagai pembangun peradaban dunia yang rahmatan lil 'âlamîn.

\section{DAFTAR PUSTAKA}

Abdulgani, Roeslan. 1963. Islam Datang Ke Nusantara Membawa Tamadun/Kecerdasan. Makalah dalam Hasymy, A.Prof. (Penyusun) 1989. Sejarah Masuk dan Berkembangnya Islam di Indonesia. Cet.II. Penerbit PT. Alma'arif, Bandung

Al-Faruqi, Ismail Raji dan Al-Faruqi, Lois Lamya. 2003. Atlas Budaya Islam, Menjelajah Khazanah Peradaban Gemilang (Edisi keempat). Penerbit Mizan, Bandung.

Tersedia Online di http://jurnal.radenfatah.ac.id/index.php/medinate 
Ansary, Tamim. 2010. Dari Puncak Baghdad, Sejarah Dunia Versi Islam (edisi pertama, diterjemahkan Yuliani Liputo). Penerbit Zaman, Jakarta.

Anshari, H. Endang Saifuddin, M.A. 1979. Ilmu, Filsafat dan Agama. Penerbit PT. Bina Ilmu, Surabaya.

Anshari, A.Yani. 2008. Tafsir Negara Islam dalam Dialog Kebangsaan di Indonesia. Diterbitkan Bidang Akademik UIN Sunan Kalijaga, Yogyakarta.

Armstrong, Karen. 2011a. Sejarah Tuhan, Kisah 4000 Tahun Pencari Tuhan Dalam AgamaAgama manusia (edisi Gold kedua). Penerbit Mizan, Bandung

Armstrong, Karen. 2011b. Masa Depan Tuhan (edisi pertama). Penerbit Mizan, Bandung

As-Sirjani, Raghib. Prof.Dr. 2011. Sumbangan Peradaban Islam Pada Dunia (diterjemahkan oleh Sonif et al.). Penerbit Pustaka Al-Kautsar, Jakarta.

Azhar, Muhammad. Drs. MA. 1997. Filsafat Politik, Perbandingan Antara Islam dan Barat. PT. RajaGrafindo Persada, Jakarta.

Azra, Azyumardi. 2000. Islam Substantif, Agar Umat Tidak Jadi Buih. Penerbit Mizan, Bandung.

Azra, Azyumardi. Kebangkitan Islam Akan Muncul dari Melayu. Jurnal Ulumul Qur'an. 1996. (1-VII) 19.

Bachar, Baghowi. Dr. 1989. Langkah Sebelum Melangkah, Upaya Menemukan Sistematika AlQur'an Menurut Al-Qur'an. Naskah Buku Belum Diterbitkan. Palembang

Bachar, Baghowi. Dr. 2005. Sistematika Al-Qur'an, Menuju Ke Metoda Penafsiran Alternatif : Tafsir Persepktif. Naskah Buku Belum Diterbitkan. Palembang

Bachar, Baghowi. Dr. 2010. Menguak Kemandegan Ilmu Tafsir. Naskah Buku Belum Diterbitkan. Palembang.

Bathuthah, Ibnu. 2012. Rihlah Ibnu Bathuthah. Penerbit Pustaka Al-Kautsar, Jakarta

Budiarjo, Miriam. Prof. 2003. Dasar-Dasar Ilmu Politik Edisi ke duapuluh lima. Penerbit PT. Gramedia Pustaka Utama, Jakarta

Bungin, Burhan. (Ed.) 2001. Metodologi Penelitian Kualitatif. PT. RajaGrafindo Persada, Jakarta.

Chodwick, Bruce.A. 1991. Metode Penelitian Ilmu-Ilmu Sosial. Diterjemahkan Silistia (Et.al). IKIP Semarang Press, Semarang.

Dahlan, Abdul Aziz. (Et.al) 1997. Ensiklopedi Hukum Islam. Penerbit PT. Ichtisar Baru Van Hoeve, Jakarta.

Effendi, Bahtiar. (2011). Islam dan Negara, Transformasi Gagasan dan Praktik Politik Islam di Indonesia (Edisi Digital). Diterjemahkan Ihsan Ali Fauzy (Et.al). Penerbit Democracy Project Yayasan Abad Demokrasi : www.abad-demokrasi.com

Esposito, John.L. (2010). Islam The Straight Path, Ragam Ekspresi Menuju Jalan Lurus. Penerbit Paramadina, Jakarta.

Furchan, Arief dan Maimun, Agus (2005). Studi Tokoh, Metode Penelitian Tokoh. Penerbit Pustaka Pelajar, Yogyakarta.

Gibb. H.A.R. (1996). Aliran-Aliran Modern Dalam Islam. Penerbit PT. RajaGrafindo Persada, Jakarta

Tersedia Online di http://jurnal.radenfatah.ac.id/index.php/medinate 
Grolier Incorporated. 1998. The Encyclopedia Americana - International Edition. Grolier Incorporated, USA

Hamid, Abdul. Drs. KH. M.Ag. dan Yaya, Drs. A.Ag. 2010. Pemikiran Modern Dalam Islam. CV.Pustaka Setia, Bandung.

Hasymi, A. Prof. 1995. Sejarah Kebudayaan Islam (edisi kelima). PT.Bulan Bintang, Jakarta.

Helmiati, Dr.Hj. M.Ag. 2011. Sejarah Islam Asia Tenggara. Penerbit Zanafa Publishing, Pekanbaru-Riau.

Iqbal, Muhammad. DR. M.Ag, et.al. 2010. Pemikiran Politik Islam Dari Masa Klasik Hingga Indonesia kontemporer, Penerbit Kencana Prenada Media Group, Jakarta.

Iqbal, Muhammad. 1983. Pembangunan Kembali Alam Pikiran Islam (edisi ketiga), Diterjemahkan Osman Raliby. Penerbit NV. Bulan Bintang, Jakarta.

Irawan, Syaiful. 1993. Studi Terhadap Pemikiran Hidajat Nataatmadja Tentang Paradigma Ilmu (Skripsi). Fakultas Ushuluddin, IAIN Raden Fatah Palembang.

Izomiddin, Dr. MA. 2013. Pemikiran dan Filsafat Hukum Islam. Rafah Press, Palembang.

Jalil, Tuanku Abdul. 1989. Poros-Aceh-Demak-Ternate. Dalam. A. Hasymy, Prof. Sejarah Masuk dan Berkembangnya Islam di Indonesia. Penerbit PT. Al-Ma'arif, Bandung

Joesoef, Daoed 2008. Serba Serbi Demokrasi. Dalam Kumpulan Karangan Daoed Joesoef. LANSKAP 2010. Diterbitkan oleh LANSKAP, Yogyakarta.

Joesoef, Daoed. 2010. Sang Teknosof Menalar Pendidikan dan Pembangunan, Kumpulan Karangan Daoed Joesoef. Penerbit LANSKAP, Yogyakarta

Karim, Abdul. M, Dr. Double M.A. 2007. Islam Nusantara : Pengaruh Nilai Keislaman Dalam Sejarah Bangsa Indonesia. Penerbit Pustaka Book Publishers, Yogyakarta

Kaelan, M.S. Prof. 2008. Pendidikan Pancasila (edisi kesembilan). Penerbit Paradigma, Yogyakarta.

Khaldun, Ibnu. 2011. Mukaddimah. Penerjemah Masturi Irham Lc. Et.al. Penerbit Pustaka AlKautsar, Jakarta.

Koentjaraningrat 1979. Kebudayaan Mentalitet dan Pembangunan (Edisi keenam). Penerbit PT. Gramedia, Jakarta

Kuntowijoyo. 1999. Identitas Politik Umat Islam. Penerbit Mizan, Bandung.

Latif, Yudi. 2011. Negara Paripurna (edisi kedua). Penerbit PT. Gramedia Pustaka Utama, Jakarta.

Lubis, Ridwan. M. 2010. Sukarno dan Modernisme Islam. Diterbitkan Komunitas Bambu, Depok.

Ma'arif, Ahmad Syafii, Ph.D. Islam, Politik dan Demokrasi Kita. Dalam Carvallo,Bosco dan Dasrizal (Ed). 1983. Aspirasi Umat Islam Indonesia. Diterbitkan LEPPENAS, Jakarta.

Madjid, Nurcholis. 1992. Islam Doktrin dan peradaban, Sebuah telaah kritis Tentang Masalah Keimanan, Kemanusiaan dan Kemoderenan (edisi kedua). Penerbit Yayasan Wakaf paramadina, Jakarta.

Madjid, Nurcholis. 2010. Islam Agama Kemanusiaan (Edisi keempat). Penerbit Paramadina, Jakarta.

Tersedia Online di http://jurnal.radenfatah.ac.id/index.php/medinate 
Mangkusasmito, Prawoto. 1970. Pertumbuhan Historis Rumus dasar Negara dan Sebuah Projeksi. Penerbit Hudaya, Djakarta

Maryam, Siti. Et al.(ed). 2009. Sejarah Peradaban Islam Dari Masa Klasik Hingga Modern. Penerbit LESFI, Solo.

Muhadjir, Noeng. Prof. Dr. H. 2000. (Edisi IV) Metode Penelitian Kualitatif. Penerbit rake Sarasin Yogyakarta.

Murod al-Brebesy, Ma'mun. 1999. Menyingkap Pemikiran Politik Gus Dur dan Amien Rais tentang Negara. PT. Raja Grafindo Persada, Jakarta.

Mulia, Musdah. 2010. Negara Islam (edisi kedua). Penerbit Katakita, Depok.

Muthahhari, Murtadha. 2009. Keadilan Ilahi, Asas Pandangan Dunia Islam (diterjemahkan oleh Agus effendi). Penerbit Mizan, Bandung.

Muhammad, Dani Efendi. 2012. Wawancar

Nataatmadja, Hidayat. Dr.Ir. 1982. Krisis Global Ilmu Pengetahuan dan Penyembuhannya. Penerbit Iqra, Bandung.

Penerbit Iqra, Bandung. 1983. Membangun Ilmu Pengetahuan Berlandaskan Ideologi. 1983. Gerakan Islam : Antara Kesemuan dan Harapan. Dalam Carvallo, Bosco dan Dasrizal (Ed). 1983. Aspirasi Umat Islam Indonesia. Diterbitkan oleh LEPPENAS, Jakarta

1984a. Pemikiran Kearah Ekonomi Humanistik. Penerbit

PLP2M, Yogyakarta.

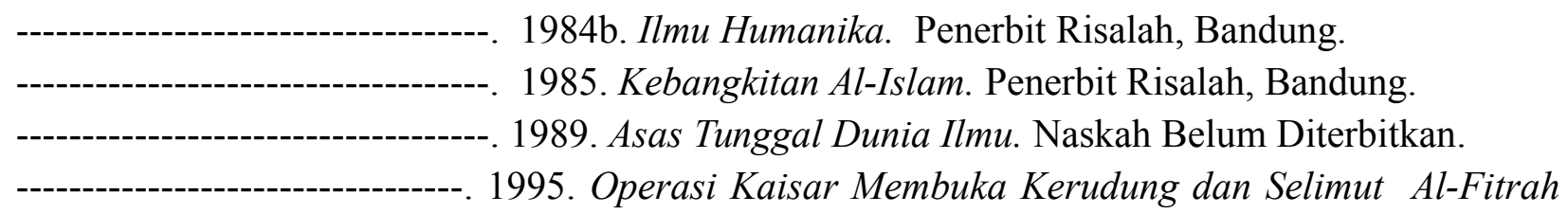

Volume 2. Naskah belum diterbitkan, Bogor.

1997. Kembalinya Si Anak Hilang Kepangkuan Al-Qur'an dan As-

Sunnah. Naskah belum diterbitkan, Bogor.

--. 2001. Inteligensi Spiritual. Penerbit Perenial Press, Jakarta.

. 2003. Proklamasi \& Revolusi Kebangkitan 1425 H. Penerbit

Intuisi Press, Jakarta.

Intuisi Press, Jakarta.

2007. Mukjizat Al-Qur'an v.s, Tahayul Iptek Seri-2. Penerbit et.al. 2007. Indonesia Bergerak, Agenda Menuju Kebangkitan.

Penerbit LANSKAP, Yogyakarta

Penerbit LANSKAP, Yogyakarta.

Nataatmadja, Hidayat. 1991. Surat Pribadi

Natsir, Mohammad. 2001. Agama dan Negara Dalam Perspektif Islam. Penerbit Media Dakwah, Jakarta.

Tersedia Online di http://jurnal.radenfatah.ac.id/index.php/medinate 
Noor, Farid Ma'ruf 1983. Islam Jalan Hidup Lurus. Penerbit PT. Bina Ilmu, Surabaya.

Nugroho, Tarli. 2010. Pengantar Kepada Pemikiran Hidayat Nataatmadja, Jurnal Hidayat Natatmadja (Online). Diterbitkan Oleh LANSKAP, Yogyakarta. (http://hidayatnataatmadja.blogspot.com/)

Oesman, Oetojo dan Alfian (ed) 1992. Pancasila Sebagai Ideologi Dalam Berbagai Bidang Kehidupan, Bermasyarakat dan Bernegara (edisi ketiga). Diterbitkan BP - 7 Pusat.

Pulungan, J.Suyuti. 2002. Fiqih Siyasah. Penerbit Rajawalipers, Jakarta.

Qudsi, Syaifudin (ed) Tanpa Tahun. Risalah Pendatang Malam, Kumpulan Hikmah Hidayat Nataatmadja. Naskah Buku Belum diterbitkan.

Rachman, Fazlur. 1992. Islam (edisi kedua). Penerbit PT. Bumi Aksara, Jakarta.

Ranawidjaja, Usep.Mr. 1960. Hukum Tatanegara Indonesia Djilid I. Penerbit Fa. Pustaka Star, Bandung

Russel, Bertrand. 2004. Sejarah Filsafat Barat dan kaitannya dengan kondisi sosio-politik dari zaman kuno hingga sekarang (edisi kedua. Diterjemahkan Sigit Jatmiko et al.). Penerbit Pustaka Pelajar, Yogyakarta.

Salam, Burhanuddin. 1996. Filsafat Pancasilaisme (Edisi Revisi). Penerbit Rineka Cipta, Bandung.

Sardar, Ziauddin. 2005. Kembali Ke Masa Depan, Syariat Sebagai Metodologi Pemecahan Masalah. Penerbit PT. Serambi Ilmu Semesta, Jakarta

Sardar, Ziauddin. 2005. Mengkaji Kembali Pemikiran Islam (Makalah) Dalam Islam Tanpa Syariat 2005. Penerbit. Grafindo Khazanah Ilmu, Jakarta.

Sardar, Ziauddin \& Davies, Merryl Wyn. (Ed). 1992. Wajah-Wajah Islam. Penerbit Mizan, Bandung.

Saefudin Buchori, Didin. Prof. Dr. 2009. Sejarah Politik Islam. Pustaka Intermasa, Jakarta.

Shihab, Quraish.M. 2009. Membumikan Al-Qur'an (edisi ketiga). Penerbit Mizan, Bandung.

Sjadzali, Munawir, H. MA. 1993. Islam dan Tata Negara. (edisi kelima). Penerbit Universitas Indonesia, Jakarta.

Soehino. 1998. Ilmu Negara, Penerbit Liberty, Yogyakarta.

Soekarno. 1947. Lahirnya Panca Sila, Pidato Pertama Tentang Panca Sila 1 Juni 1945, Arena Ilmu, Jakarta

Sou'yb, Joesoef 1983. Agama-agama Besar Dunia. Penerbit Pustaka Alhusna, Jakarta.

Stoddard, Lothrop. M.A., PhD. 1966. Dunia Baru Islam. Diterbitkan Menko Kesedjahteraan RI, Jakarta

Suhelmi, Ahmad. MA. 2002. Polemik Negara Islam Soekarno Versus Natsir. Penerbit Teraju, Jakarta.

Suryanegara, Ahmad Mansur. 2009. Api Sejarah (Jilid 1). Salamadani Pustaka Semesta, Bandung.

Surwandono, S.Sos. M.Si. 2001. Pemikiran Politik Islam. Penerbit LPPI.UMY, Yogyakarta.

Syafii Ma'arif, Ahmad. 1985. Islam dan Masalah Kenegaraan,Studi Tentang Percaturan Dalam Konstituante. Penerbit LP3ES, Jakarta.

Tersedia Online di http://jurnal.radenfatah.ac.id/index.php/medinate 
Medina-Te, Vol. 13 Nomor 2, Juni 2017

ISSN: $1858-323$

Tohir, Muhammad. 1981. Sejarah Islam Dari Andalus Sampai Indus. PT. Dunia Pustaka Jaya, Jakarta.

Ulumul Qur'an, Jurnal Ilmu dan Kebudayaan, Nomor 1. Volume IIV, Tahun 1996. Diterbitkan Lembaga Studi Agama dan Filsafat, Jakarta. 